\title{
Factors Affecting Enzymatic Hydrolysis from Pretreated Fibre Pressed Oil Palm Frond Using Sacchariseb C6
}

\author{
Fatin Syazwana Hashim, ${ }^{1}$ Wan Mohd Hafizuddin Wan Yussof, ${ }^{1 *}$ Mah Kah Hong, ${ }^{1}$ \\ Nurul Fatihah Mohamad Roli, ${ }^{1}$ Syed Mohd Saufi Tuan Chik, ${ }^{1}$ \\ Mazrul Nizam Abu Seman ${ }^{1}$ and Abdul Wahab Mohammad ${ }^{2}$
}
${ }^{1}$ Faculty of Chemical and Natural Resources Engineering, Universiti Malaysia Pahang, Lebuhraya Tun Razak, 26300 Kuantan, Pahang, Malaysia
${ }^{2}$ Department of Chemical and Process Engineering, Faculty of Engineering and Built Environment, Universiti Kebangsaan Malaysia, 43600 Bangi, Selangor, Malaysia

*Corresponding author: hafizuddin@ump.edu.my

Published online: 15 February 2017

To cite this article: Hashim, F. S. et al. (2017). Factors affecting enzymatic hydrolysis from pretreated fibre pressed oil palm frond using sacchariseb C6. J. Phys. Sci., 28(Supp. 1), 281-295, https://doi.org/10.21315/jps2017.28.s1.19

To link to this article: https://doi.org/10.21315/jps2017.28.s1.19

\begin{abstract}
In this study, fibre pressed oil palm frond (FPOPF) was introduced as the raw material for the production of glucose using Sacchariseb C6 to maximise the utilisation of oil palm waste. Sacchariseb C6 is a commercial cellulase blended enzyme from Advanced Enzymes Technology. In order to achieve maximum glucose production, a factorial analysis $2^{5-1}$ using response surface methodology (RSM) was employed to screen the best enzymatic hydrolysis condition by varying the parameters such as agitation speed, enzyme loading, glucan loading, temperature and hydrolysis time. FPOPF was treated with $4.42 \%(w / v)$ of sodium hydroxide at $100^{\circ} \mathrm{C}$ prior to the enzymatic hydrolysis. Raw FPOPF consists of $40.7 \%$ glucan, 26.1\% xylan, 26.2\% lignin, $1.8 \%$ ash and $4.5 \%$ extractives. On the other hand, pretreated FPOPF consists of $61.4 \%$ glucan, 20.4\% xylan, $13.3 \%$ lignin, $1.3 \%$ ash and $0.3 \%$ extractives. From this study, it was found that the best enzymatic hydrolysis condition yielded $33.01 \pm 0.73 \mathrm{~g} / \mathrm{L}$ of glucose when performed at $200 \mathrm{rpm}$ of agitation speed, $60 \mathrm{FPU} / \mathrm{mL}$ of enzyme loading, $4 \%(w / w)$ of glucan loading, temperature at $55^{\circ} \mathrm{C}$ and $72 \mathrm{~h}$ of reaction time. The model obtained from RSM was significant with p-value $<0.0001$. It is suggested that this model had a maximum point which is likely to be the optimum point and possible for the optimisation process.
\end{abstract}

Keywords: Enzymatic hydrolysis, fibre pressed oil palm frond, sacchariseb C6, factorial analysis, response surface methodology 


\section{INTRODUCTION}

Lignocellulosic biomass (LCB) is one of the most abundant renewable biomasses comprising of cellulose, hemicellulose and lignin. ${ }^{1,2}$ Commonly, most of the agricultural LCB consists of about 10\%-25\% lignin, 20\%-30\% hemicellulose, and $40 \%-50 \%$ cellulose. ${ }^{3}$ However, the distribution of each component varies significantly between different plants. ${ }^{4}$ These differences may due to the different types of plant, sources, ages and others. Different geographic locations, climate, and soil conditions can also be the reasons for the variations in the chemical composition among them. ${ }^{5,6}$

In this study, fibre pressed oil palm frond (FPOPF) was introduced as a raw material where the hemicellulose and cellulose were converted into simple sugars. In order to improve the accessibility of cellulase enzyme on FPOPF, the structure of the lignocellulose must be broken down, i.e., by alkaline pretreatment. In alkaline pretreatment, the alteration of the lignin structure in biomass is achieved by degrading ester and glycosidic side chains of the biomass using alkaline solvent, leading to swelling as well as de-crystallisation of cellulose. ${ }^{7,8}$ Sacchariseb C6 which is a blended cellulase enzyme was used in enzymatic hydrolysis for the production of glucose by breaking down of cellulose molecule into simple sugar.

Therefore, this study aims to present a systematic study on the effect of simultaneous changes of synthesis conditions on glucose production using Sacchariseb C6 and thus, finding the best enzymatic hydrolysis condition using statistical approach of response surface methodology (RSM). Screening design was used to study potentially affective parameters by identify the dominant and significant factors contribute to the enzymatic hydrolysis.

\section{EXPERIMENTAL}

\subsection{Materials}

Oil palm frond (OPF) was collected from a local palm oil plantation at Kuantan, Pahang, Malaysia. The OPF was pressed by using sugarcane machine to separate juices from the fibre. The FPOPF was dried under the sun for 2-3 days until constant weight. Then, FPOPF was shredded into pieces and sieved into particle size less than $2 \mathrm{~mm}$. The dried FPOPF was stored in sealed plastic bag at room temperature. Enzymatic hydrolysis was carried out using blended cellulase enzyme namely Sacchariseb C6, an industrial grade commercial enzyme obtained from Advanced Enzyme Technology (India). 


\subsection{Compositional Analysis of FPOPF}

FPOPF was characterised to determine the composition of glucan, xylan, lignin, extractive and ashes contents. The analysis was carried out according to National Renewable Energy Laboratory (NREL) methods. ${ }^{9-12}$ The compositional characterisation analysis was performed on both the untreated FPOPF and pretreated FPOPF.

Moisture content analysis was carried out using A\&D MS70 moisture analyser (DSC, UK) while ash content analysis was conducted using a furnace at using muffle furnace at $575^{\circ} \mathrm{C} \pm 25^{\circ} \mathrm{C}$ for $24 \pm 6 \mathrm{~h}$. The extractives content was measured using DIONEX ASE 350 (Thermo Scientific, USA) with water and ethanol as solvents for $30 \mathrm{~min}$. The recovered water extract was analysed to determine the soluble sugar content in the FPOPF. Meanwhile, ethanol extracts were used to determine the ethanol extractive that includes chlorophyll, proteins fats and oils. Analysis on acid insoluble lignin and acid soluble lignin were determined using two-step acid hydrolysis. The acid insoluble material was determined using gravimetric analysis while UV-Vis spectroscopy was used to measure acid soluble lignin in FPOPF. ${ }^{13}$

\subsection{Alkaline Pretreatment}

Referring to Sukri and Rahman, ${ }^{7}$ the FPOPF sample was soaked in sodium hydroxide $(\mathrm{NaOH})$ solution with concentration $4.42 \%(\mathrm{w} / \mathrm{v}) .^{7}$ The sample was treated at $100^{\circ} \mathrm{C}$ for about $58.31 \mathrm{~min}$. Then, the treated FPOPF was washed thoroughly with de-ionised water until turned to neutral. It was dried in the oven at $105^{\circ} \mathrm{C}$ and stored for further analysis.

\subsection{Enzymatic Hydrolysis}

Prior to the enzymatic hydrolysis, the moisture content of pretreated FPOPF should be less than $5 \%$. The pretreated FPOPF $(1 \%-4 \% \mathrm{w} / \mathrm{v})$ was weighed using analytical balance and added into $20 \mathrm{~mL}$ scintillation vial containing $0.02 \%(\mathrm{w} / \mathrm{v})$ sodium azide and $0.05 \mathrm{M}$ citrate buffer at $\mathrm{pH}$ 4.8. Sodium azide was added to prevent microbial growth. Then, the mixture was pre-incubated at certain temperature $\left(35^{\circ} \mathrm{C}-55^{\circ} \mathrm{C}\right)$ prior to the addition of enzymes. The enzymatic hydrolysis was then initiated by adding Sacchariseb C6 (20-60 FPU/ml) and Novozyme 188 (64 pNPGU/mL). The incubator shaker started to agitate at ranges 50 to $200 \mathrm{rpm}$. At the end of the hydrolysis (3-72 h), the samples were filtered for further analysis. Each experiment was carried out in triplicate. 


\subsection{Experimental Design}

The experimental design for factorial analysis was performed using Design Expert 7.0.0 (Stat-Ease Inc., USA) software. Five independent factors as shown in Table 1 were analysed using RSM. The condition ranges chosen were based on the other researcher's previous work. ${ }^{14-17}$ The factors were constructed in half level factorial designs of $2^{5-1}$ to screen their effect on the response of glucose production.

Table 1: Parameters and their designated low and high value.

\begin{tabular}{lccc}
\hline Factor & Units & Low value $(-1)$ & High value $(+1)$ \\
\hline A: Agitation speed & $\mathrm{rpm}$ & 50 & 200 \\
B: Enzyme loading & $\mathrm{FPU} / \mathrm{mL}$ & 20 & 60 \\
C: Glucan loading & $\%$ & 1 & 4 \\
D: Temperature & ${ }^{\circ} \mathrm{C}$ & 35 & 55 \\
E: Reaction time & $\mathrm{h}$ & 3 & 72 \\
\hline
\end{tabular}

The validation run for factorial analysis was carried by comparing the experimental values with the predicted model generated by Design Expert software. The condition for the validation run was obtained from the predicted best condition developed from $2^{5-1}$ factorial design. The percentage of error was calculated using Equation 1.

$$
\begin{aligned}
& \text { Percentage } \\
& \text { of error, } \%
\end{aligned}=\frac{\mid \text { Predicted value-Experimental value } \mid}{\text { Experimental value }} \times 100
$$

\subsection{HPLC Analysis}

The hydrolysate was determined using Agilent 1200 high performance liquid chromatography (HPLC) system equipped with refractive index (RI) detector. The column used was RHM Monosaccharide $\mathrm{H}+$ column. Pure water was used as the mobile phase prepared using Milli-Q ultrapure water (Millipore, USA). The column temperature was maintained at $60^{\circ} \mathrm{C}$. The flow rate of $0.4 \mathrm{~mL} / \mathrm{min}$ and $5 \mu \mathrm{L}$ injection volume was used. Hydrolysate samples and standards were filtered using $0.22 \mu \mathrm{m}$ syringe filter before HPLC analysis. The calibration curve was prepared with the ranges of $1 \mathrm{~g} / \mathrm{L}$ to $40 \mathrm{~g} / \mathrm{L}$. 


\section{RESULTS AND DISCUSSION}

\subsection{Composition of FPOPF}

The characterisation of FPOPF was carried out for untreated and pretreated FPOPF according to NREL's methods. Untreated FPOPF refers to the biomass without any pretreatment applied on it. Whereas, pretreated FPOPF refers to the biomass that undergoes alkaline pretreatment. The compositional analysis of both FPOPF were analysed in terms of glucan, xylan, lignin, ashes and extractives as shown in Table 2. The total structural carbohydrate content for untreated FPOPF was found to be $66.8 \%$ with $40.7 \%$ of glucan as the major structural carbohydrate followed $26.1 \%$ of xylan. Meanwhile, pretreated FPOPF shown $81.8 \%$ of total carbohydrates comprise of $61.4 \%$ glucan and $20.4 \%$ xylan. An increase of glucan but a reduction of xylan could be seen because of the outer layer was disrupted during alkaline pretreatment caused by partial removal of lignin and hemicellulose resulting exposure of cellulose fibers. Lower yield of lignin was observed after alkaline pretreatment which proved that alkaline pretreatment caused the delignification to occur.

Table 2: Differences in composition of untreated and pretreated FPOPF.

\begin{tabular}{lcc}
\hline Composition & Native FPOPF $(\%)$ & Pre-treated FPOPF (\%) \\
\hline Total carbohydrates & 66.8 & 81.8 \\
Glucan & 40.7 & 61.4 \\
Xylan & 26.1 & 20.4 \\
Lignin & 26.2 & 13.3 \\
Ashes & 1.8 & 1.3 \\
Extractives & 4.5 & 0.3 \\
\hline
\end{tabular}

\subsection{Screening of Enzymatic Hydrolysis}

The experimental design of half level factorial analysis was carried out to determine the factors affecting production of glucose during enzymatic hydrolysis. These five factors include agitation speed, enzyme loading, glucan loading, temperature, and hydrolysis time. Table 3 clearly shows that the highest production of glucose was obtained at $33.01 \pm 0.73 \mathrm{~g} / \mathrm{L}$ where the conditions at $200 \mathrm{rpm}$ of agitation speed with temperature of $55^{\circ} \mathrm{C}, 4 \%$ of glucan loading, and $60 \mathrm{FPU} / \mathrm{mL}$ of enzyme loading for $72 \mathrm{~h}$ in hydrolysis time. 
Table 3: Experimental design for factorial analysis with its response.

\begin{tabular}{ccccccc}
\hline \multirow{2}{*}{$\begin{array}{c}\text { Std. } \\
\text { order }\end{array}$} & $\begin{array}{c}\text { Agitation } \\
\text { speed } \\
(\mathrm{rpm})\end{array}$ & $\begin{array}{c}\text { Enzyme } \\
\text { loading } \\
(\text { FPU/mL })\end{array}$ & $\begin{array}{c}\text { Glucan } \\
\text { loading } \\
(\%)\end{array}$ & $\begin{array}{c}\text { Temp. } \\
\left({ }^{\circ} \mathrm{C}\right)\end{array}$ & $\begin{array}{c}\text { Hydrolysis } \\
\text { time } \\
(\mathrm{h})\end{array}$ & $\begin{array}{c}\text { Glucose } \\
\text { concentration } \\
(\mathrm{g} / \mathrm{L})\end{array}$ \\
\hline 1 & 50 & 20 & 1 & 35 & 72 & 7.71 \\
2 & 200 & 20 & 1 & 35 & 3 & 3.23 \\
3 & 50 & 60 & 1 & 35 & 3 & 3.08 \\
4 & 200 & 60 & 1 & 35 & 72 & 8.91 \\
5 & 50 & 20 & 4 & 35 & 3 & 11.39 \\
6 & 200 & 20 & 4 & 35 & 72 & 30.76 \\
7 & 50 & 60 & 4 & 35 & 72 & 26.55 \\
8 & 200 & 60 & 4 & 35 & 3 & 14.04 \\
9 & 50 & 20 & 1 & 55 & 3 & 3.16 \\
10 & 200 & 20 & 1 & 55 & 72 & 7.47 \\
11 & 50 & 60 & 1 & 55 & 72 & 9.92 \\
12 & 200 & 60 & 1 & 55 & 3 & 3.76 \\
13 & 50 & 20 & 4 & 55 & 72 & 30.32 \\
14 & 200 & 20 & 4 & 55 & 3 & 14.63 \\
15 & 50 & 60 & 4 & 55 & 3 & 13.99 \\
16 & 200 & 60 & 4 & 55 & 72 & 33.01 \\
\hline
\end{tabular}

\subsection{Model Fitting}

In factorial analysis, the contribution of the main factor gives an important effect in the optimisation. Two to three highest contributing factors will be selected from this factorial analysis for the optimisation part later. All five factors (A, B, C, D and $\mathrm{E}$ ) gave a positive effect (refer to orange bar chart) to the production of glucose as shown in Figure 1. It is suggested that the highest values will be used to favour the response. For main effects, an effect is said to be positive when an increase to its high level will cause an increase in the response, while negative effect is when an increase to its high level will result a decrease in the response. Meanwhile, the negative effect (blue bar chart) reveals that the use of the lowest range value of factor will increase conversion to glucose. 


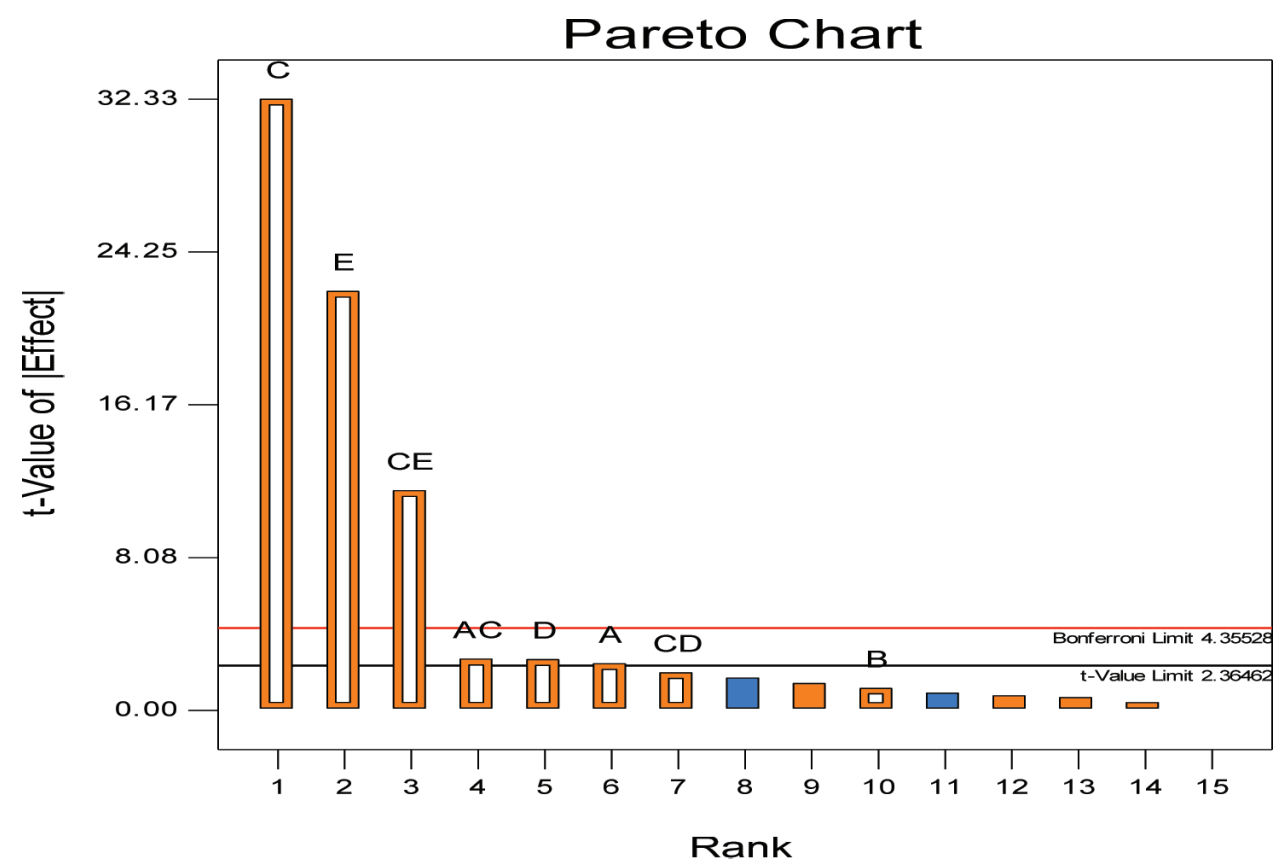

Figure 1: Pareto chart.

The relative size of effects is shown in Pareto chart, where the bar length is proportional to the absolute value of estimated effect. Effects of t-value limit (black line) are considered statistically significant at $95 \%$ confidence level whereas the effects below t-value limit are not likely to be significant. Effect above Bonferroni's corrected t-value limit (red line) is almost certainly significant. A quick analysis was performed on the selected effects using Pareto chart to statistically check for significance of the selected effects at $95 \%$ confidence level. All the selected effects (A, B, C, D, E, AC, CD, and CE) shown to be significant at both t-value limit and Bonferroni's corrected t-value limit.

\subsection{Analysis of Variance (ANOVA)}

The analysis of variance (ANOVA) was carried out to determine the significant effect of the model in this enzymatic hydrolysis process. The model obtained was significant with $p$-value $<0.0001$ as shown in Table 4 . A good fitting model can be determined by the value of the coefficient of determination $\left(\mathrm{R}^{2}\right)$ more than $0.80 .{ }^{18} \mathrm{In}$ this study, $\mathrm{R}^{2}$ value obtained in this model was 0.9959 , which is in good agreement with the adjusted $R^{2}$ value of 0.9912 . The high $R^{2}$ value of 0.9959 indicates that the model was well adapted to the response. 
Table 4: ANOVA for factorial analysis.

\begin{tabular}{ccccccc}
\hline Source & $\begin{array}{c}\text { Sum of } \\
\text { square }\end{array}$ & $\begin{array}{c}\text { Degree of } \\
\text { freedom }\end{array}$ & Mean square & F-value & P-value & \\
\hline Model & 1648.46 & 8 & 206.06 & 212.19 & $<0.0001$ & significant \\
A & 5.90 & 1 & 5.90 & 6.07 & 0.0432 & \\
B & 1.32 & 1 & 1.32 & 1.35 & 0.2827 & \\
C & 1015.19 & 1 & 1015.19 & 1045.39 & $<0.0001$ & \\
D & 6.99 & 1 & 6.99 & 7.20 & 0.0314 & \\
E & 476.94 & 1 & 476.94 & 491.12 & $<0.0001$ & \\
AC & 7.11 & 1 & 7.11 & 7.32 & 0.0304 & \\
CD & 3.86 & 1 & 3.86 & 3.97 & 0.0865 & \\
CE & 131.16 & 1 & 131.16 & 135.06 & $<0.0001$ & \\
Residual & 6.80 & 1 & 0.97 & & & \\
\hline
\end{tabular}

Equation 2 shows the response surface quadratic model for glucose production which can be presented in terms of coded factors as in the following equation:

$$
\begin{aligned}
Y= & 13.87+0.61 \mathrm{~A}+0.29 \mathrm{~B}+7.97 \mathrm{C}+0.66 \mathrm{D}+5.46 \mathrm{E} \\
& +0.67 \mathrm{AC}+0.49 \mathrm{CD}+2.86 C E
\end{aligned}
$$

where,

$Y=$ concentration of glucose $(\mathrm{g} / \mathrm{L})$,

$A=$ agitation speed (rpm),

$B=$ enzyme loading $(\mathrm{FPU} / \mathrm{ml})$,

$C=$ glucan loading $(\% \mathrm{w} / \mathrm{v})$,

$D=$ temperature $\left({ }^{\circ} \mathrm{C}\right)$, and

$E=$ hydrolysis time (h)

The unknowns $A, B, C, D$, and $E$ were referred to the main effects while $A C$, $C D$ and $C E$ were the interaction effects contributed in the enzymatic hydrolysis process. Based on the quadratic model, coefficients of $A$ to $E$ are small compared to constant. This gives an indicator that the model equation is good with small error and can be used for further analysis.

\subsection{Comparison of Actual versus Predicted Graph}

A regression model can be used to predict expected new observations on the glucose production corresponding to experimental values of the factors. Meanwhile, the data that extrapolate beyond the straight line generated by Design Expert is highly 
possible that a model is no longer fit well in the regression model. The experimental data for the production of glucose from the empirical model is in good agreement with the observed ones in the range of the operating factors as shown in Figure 2.

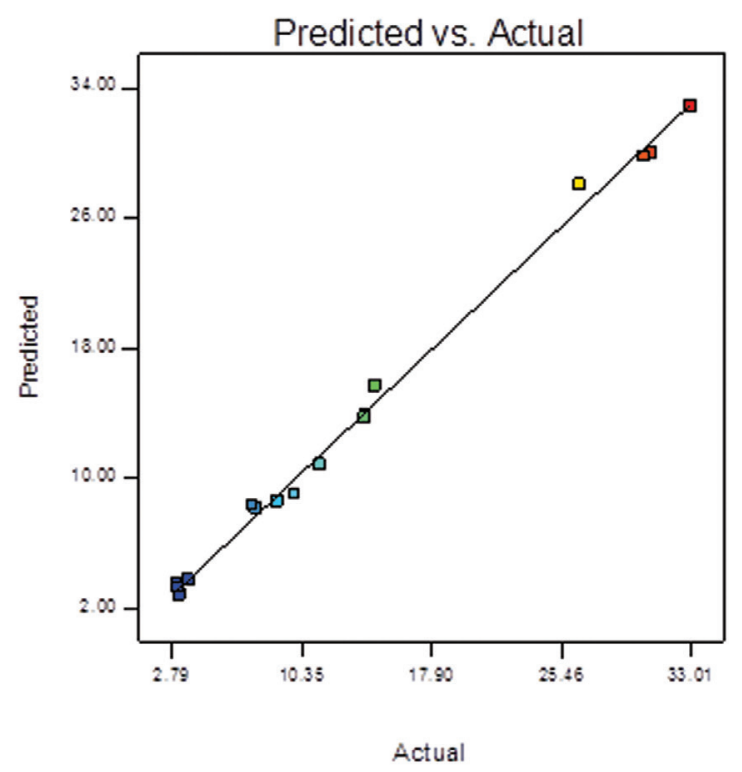

Figure 2: Predicted versus actual regression model graph.

\subsection{Effect of Interfacial Polymerisation Factors on the Glucose Production}

The interaction effect plot was generated to represent the results of the regression analysis. It was represented the deviations of the average between the high and low levels for each factors.

\subsubsection{Interaction between time and glucan loading}

The interaction between glucan loading and time (CE) gives highest contribution of $7.92 \%$ to the enzymatic hydrolysis process, as shown in Figure 3. The amount of glucose after enzymatic hydrolysis was higher at $72 \mathrm{~h}$ compared to $3 \mathrm{~h}$. In this study, having longer reaction time with high glucan loading was more beneficial because it has huge positive effect on glucose production and allowed the enzyme to hydrolyse more cellulose in FPOPF will be converted into monomer. Thus, prolong the hydrolysis time will increase the glucose production. Similar trend was obtained by Tan and Lee ${ }^{16}$ and Zheng et al. ${ }^{13} \mathrm{~A}$ comparison of results based on two different hydrolysis time reveals glucan and time are interrelated in increasing the glucose production. 
Design-Expert@ Software

Glucose concentration

- E- 3.000

$\Delta E+72.000$

$\mathrm{X} 1=\mathrm{C}:$ Glucan loading

$\mathrm{X} 2=\mathrm{E}:$ Time

Actual Factors

A: Agitation speed $=125.00$

B: Enzyme loading $=40.00$

D: Temperature $=50.00$

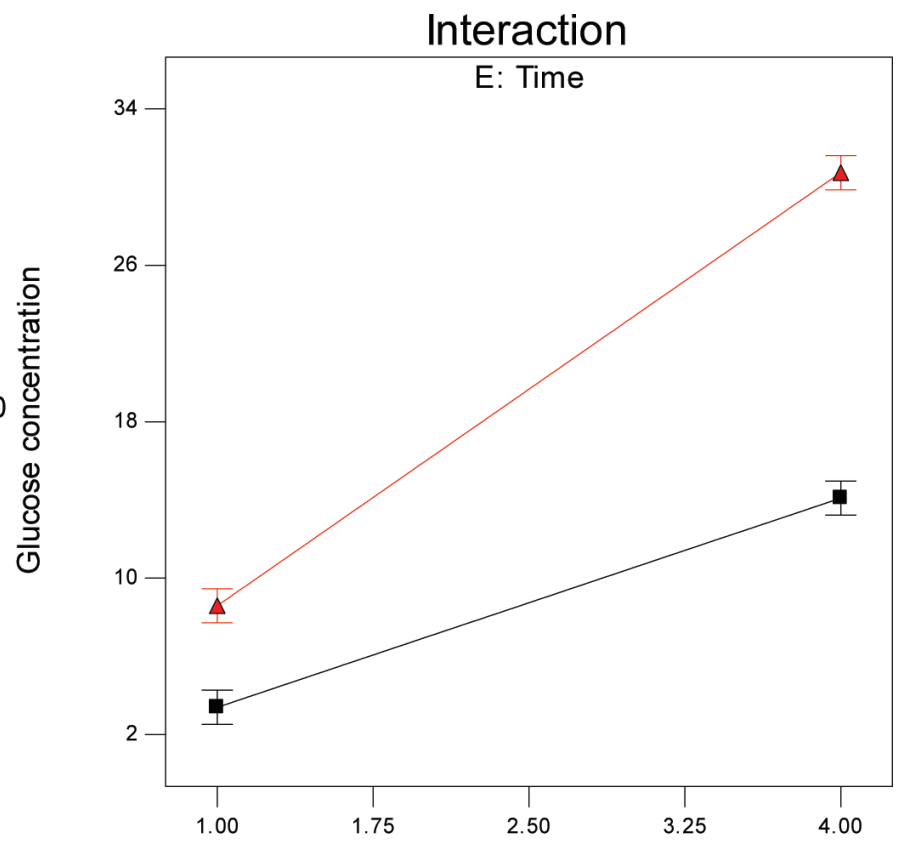

C: Glucan loading

Figure 3: Effect of glucan loading and time to the glucose production.

\subsubsection{Interaction between glucan loading and agitation speed}

Guo et al. explained that increase of agitation speed from $0 \mathrm{rpm}$ to $150 \mathrm{rpm}$ will increase the initial hydrolysis rates and final sugar concentration. ${ }^{15}$ However, Champagne and Li stated that mixing rate above $200 \mathrm{rpm}$ resulted in decreased enzymatic hydrolysis due to the shear-induced deactivation of cellulose occurred. ${ }^{18}$ Figure 4 shows the second interaction between agitation speed and glucan loading (AC) that gives $0.43 \%$ of contribution in enzymatic hydrolysis. In this present study, it was found that the glucan loading highly affected the enzymatic hydrolysis from FPOPF. There was a huge difference between low and high glucan loading at different agitation speed in the production of glucose. At lower glucan loading $(1 \% \mathrm{w} / \mathrm{v})$, no significant effect to the production of glucose can be observed either at low or high agitation speed, but not the case at high glucan loading $(4 \% \mathrm{w} / \mathrm{v})$. An increase of glucose production under agitation condition at high solid loading was due to the enhancement of mass transfer and cellulase diffusion. ${ }^{20}$ Thus, at high glucan loading $(4 \% \mathrm{w} / \mathrm{v})$ with high mixing rate of $200 \mathrm{rpm}$ can promote more cellulose to be hydrolysed to glucose because of the sufficient mixing between FPOPF and cellulase. 
Design-Expert@ Software

Glucose concentration

- C- 1.000

$\Delta \mathrm{C}+4.000$

$\mathrm{X} 1=\mathrm{A}:$ Agitation speed

X2 = C: Glucan loading

Actual Factors

B: Enzyme loading $=40.00$

D: Temperature $=50.00$

E: Time $=37.50$

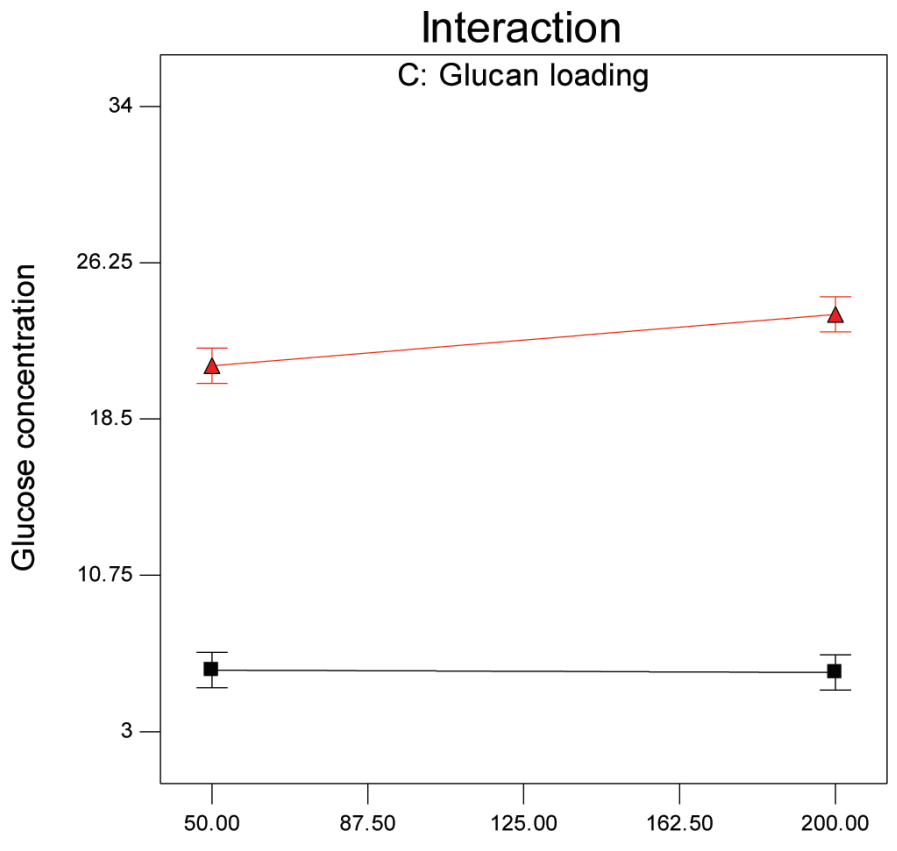

A: Agitation speed

Figure 4: Effect of agitation speed and glucan loading to the glucose production.

\subsubsection{Interaction between temperature and glucan loading}

Another interaction can be seen between glucan loading and temperature (CD) as plotted in Figure 5. The temperatures at $35^{\circ} \mathrm{C}$ and $55^{\circ} \mathrm{C}$ do not give any obvious effect on the glucose production. However, an increase in temperature of the incubator shaker during enzymatic hydrolysis at high glucan loading (4\% $\mathrm{w} / \mathrm{v})$ drastically improves the glucose production. This might due to the positive relationship between adsorption and hydrolysis of FPOPF occurred excellently at high temperatures $\left(55^{\circ} \mathrm{C}\right)$. The enzyme-substrate interaction performed the best activity at $55^{\circ} \mathrm{C}$ resulting in increase of glucose production. Overall, high glucan loading $(4 \% \mathrm{w} / \mathrm{v})$ with temperature either at $35^{\circ} \mathrm{C}$ or $55^{\circ} \mathrm{C}$ resulted almost same level of hydrolysis efficiency in order to produce high amount of glucose. Similar results reported by Tan and Lee and Nieves et al. where the glucose yield was gradually increased as the substrate loading increased. ${ }^{16,20}$ 
Design-Expert@ Software

Glucose concentration

- D- 35.000

$\Delta \mathrm{D}+55.000$

$\mathrm{X} 1=\mathrm{C}:$ Glucan loading $\mathrm{X} 2$ = D: Temperature

Actual Factors

A: Agitation speed $=125.00$

B: Enzyme loading $=40.00$

$\mathrm{E}:$ Time $=37.50$

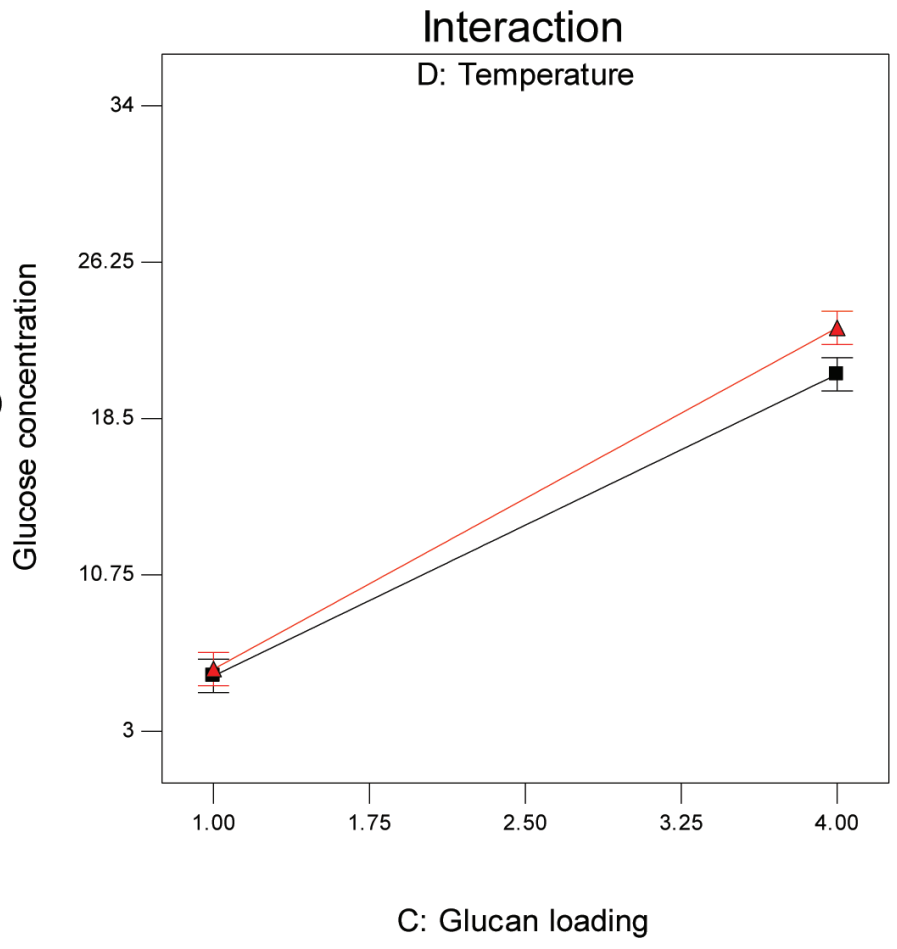

D: Temperature

C: Glucan loading

Figure 5: Effect of glucan loading and temperature to the glucose production.

\subsection{Validation Run of Factorial Analysis}

The validation experiments were conducted in triplicate based on suggested best condition by Design Expert 7.0. The experiments were carried out at $160 \mathrm{rpm}$ of agitation speed, $20 \mathrm{FPU} / \mathrm{mL}$ of Sacchariseb C6, glucan loading at 4\%, temperature at $56^{\circ} \mathrm{C}$ and hydrolysis time at $72 \mathrm{~h}$. The error from these validations runs was in between $1.85 \%$ to $4.70 \%$ as presented in Table 5 . The model was found to be in good agreement with the experimental values with error less than $10 \%$.

Table 5: Validation run for factorial analysis.

\begin{tabular}{lccc}
\hline \multirow{2}{*}{ Description } & \multicolumn{3}{c}{ Concentration of glucose $(\mathrm{g} / \mathrm{L})$} \\
\cline { 2 - 4 } & Run 1 & Run 2 & Run 3 \\
\hline Predicted value & 34.024 & 34.024 & 34.024 \\
Experimental value & 33.393 & 32.423 & 33.382 \\
Error & $1.85 \%$ & $4.70 \%$ & $1.88 \%$ \\
\hline
\end{tabular}




\section{CONCLUSION}

FPOPF is a promising feedstock for the production of fermentable sugar due to its high biomass yield and potential fermentable sugar yield from bagasse. Sacchariseb C6 was performed excellently well in the enzymatic hydrolysis of pretreated FPOPF at high glucan loading $(4 \% \mathrm{w} / \mathrm{v})$ and moderate temperature $\left(55^{\circ} \mathrm{C}\right)$. The results obtained from this study showed the best condition for the enzymatic hydrolysis was at $33.01 \pm 0.73 \mathrm{~g} / \mathrm{L}$ of glucose, $200 \mathrm{rpm}$ of agitation speed, $60 \mathrm{FPU} /$ $\mathrm{mL}$ of enzyme loading, $4 \%(\mathrm{w} / \mathrm{v})$ of glucan loading, temperature at $55^{\circ} \mathrm{C}$ and $72 \mathrm{~h}$ of hydrolysis time. Based on the quadratic model, coefficients of $\mathrm{X}_{1}$ to $\mathrm{X}_{5}$ are small compared to the constant. This gives an indicator that the model equation obtained in this study was good with small error and might had a maximum point which is likely to be the optimum point and possible for the optimisation process later. The model was found to be in good agreement with the experimental values with the error obtained from validations runs was less than $5 \%$.

\section{ACKNOWLEDGEMENTS}

The authors gratefully acknowledge financial support from the RACE grant RDU151304 and the Faculty of Chemical and Natural Resources Engineering, University Malaysia Pahang (UMP) that made this work possible. The authors also wish to acknowledge the Ministry of Education Malaysia for sponsoring postgraduate study via MyBrain15 programme.

\section{REFERENCES}

1. Loow, Y. L. et al. (2015). Recent advances in the application of inorganic salt pretreatment for transforming lignocellulosic biomass into reducing sugars. J. Agri. Food Chem., 63(38), 8349-8363, https://doi.org/10.1021/ acs.jafc.5b01813.

2. Loow, Y. L. et al. (2016). Role of energy irradiation in aiding pretreatment of lignocellulosic biomass for improving reducing sugar recovery. Cellul., 23(5), 2761-2789, https://doi.org/10.1007/s10570-016-1023-x.

3. Kumar, P. et al. (2009). Methods for pretreatment of lignocellulosic biomass for efficient hydrolysis and biofuel production. Ind. Eng. Chem. Res., 48(8), 3713-3729, https://doi.org/10.1021/ie801542g.

4. Jørgensen, H., Kristensen, J. B. \& Felby, C. (2007) Perspective: Jatropha cultivation in southern India: Assessing farmers' experiences. Biofuels, Bioprod. Biorefin., 6, 246-256. 
5. Han, J. S. \& Rowell, J. S. (1997). Chemical composition of fibers. In Rowell, R. M. et al. (Eds). Paper and composites from agro-based resources, 83134. New York: CRC Lewis Publishers.

6. Michelin, M. \& Teixeira, J. A. (2016). Liquid hot water pretreatment of multi feedstocks and enzymatic hydrolysis of solids obtained thereof. Biores. Technol., 216, 862-869, https://doi.org/10.1016/j.biortech.2016.06.018.

7. Sukri, S. \& Rahman, R. (2014). Optimization of alkaline pretreatment conditions of oil palm fronds in improving the lignocelluloses contents for reducing sugar production. Rom. Biotechnol. Lett., 19, 9006-9018.

8. Loow, Y. L. et al. (2016). Typical conversion of lignocellulosic biomass into reducing sugars using dilute acid hydrolysis and alkaline pretreatment. Cellul., 23(3), 1491-1520, https://doi.org/10.1007/s10570-016-0936-8.

9. Hames, B. et al. (2008). Preparation of samples for compositional analysis Laboratory Analytical Procedure (LAP). National Renewable Energy Laboratory, US Department of Energy, Washington.

10. Sluiter, A. et al. (2008). Determination of insoluble solids in pretreated biomass material. Technical report, March, National Renewable Energy Laboratory, US Department of Energy, Washington.

11. Sluiter, A. et al. (2008). Determination of extractives in biomass. Technical report, January, National Renewable Energy Laboratory, US Department of Energy, Washington.

12. Sluiter, A. et al. (2012). Determination of structural carbohydrates and lignin in biomass. Laboratory Analytical Procedure, National Renewable Energy Laboratory, US Department of Energy, Washington.

13. Zheng, J. et al. (2014). Enzymatic hydrolysis of steam exploded corncob residues after pretreatment in a twin-screw extruder. Biotechnol. Reports, 3 , 99-107, https://doi.org/10.1016/j.btre.2014.06.008.

14. Ramos, L. P. et al. (2014). Enzymatic hydrolysis of steam-exploded sugarcane bagasse using high total solids and low enzyme loadings. Biores. Technol., 175(C), 195-202.

15. Guo, H. et al. (2015). Co-optimization of sugar yield and input energy by the stepwise reduction of agitation rate during lignocellulose hydrolysis. Food Bioprod. Process., 95,1-6, https://doi.org/10.1016/j.fbp.2015.03.005.

16. Tan, I. S. \& Lee, K. T. (2014). Enzymatic hydrolysis and fermentation of seaweed solid wastes for bioethanol production: An optimization study. Energy, 78, 53-62, https://doi.org/10.1016/j.energy.2014.04.080.

17. Karazhiyan, H., Razavi, S. M. A. \& Phillips, G. O. (2011). Extraction optimization of a hydrocolloid extract from cress seed (Lepidium sativum) using response surface methodology. Food Hydrocol., 25, 915-920, https://doi.org/10.1016/j.foodhyd.2010.08.022. 
18. Champagne, P. \& Li, C. (2009). Enzymatic hydrolysis of cellulosic municipal wastewater treatment process residuals as feedstocks for the recovery of simple sugars. Bioresour. Technol., 100, 5700-5706, https://doi. org/10.1016/j.biortech.2009.06.051.

19. Kristensen, J. B., Felby, C. \& Jørgensen, H. (2009). Yield-determining factors in high-solids enzymatic hydrolysis of lignocellulose. Biotechnol. Biofuels, 2(1), 11, https://doi.org/10.1186/1754-6834-2-11.

20. Nieves, D. C. et al. (2016). Enzymatic hydrolysis of chemically pretreated mango stem bark residues at high solid loading. Ind. Crops Prod., 83, 500508, https://doi.org/10.1016/j.indcrop.2015.12.079 
